\title{
Animal-experimenter interaction and open-field behavior: The rat
}

JOHN KENYON, DEPARTMENT OF PSYCHOLOGY, COLBY COLLEGE, Waterville, Maine 04901

In a preliminary study rats showed a high consistency in order of being picked up in the dark from a feeding stand. The present study shows the consistency to be independent of prior behavioral treatment or surgical procedures. Although open-field tests do differentiate between groups differing in prior behavioral treatment they do not differentiate between order of picking up. A partial exploration of dominance suggests this variable may be related to order of picking up.

\section{Problem}

In a preliminary control procedure for an experiment requiring dark adaptation of rats it was found that the order of picking up the Ss in the dark from a feeding stand showed a high correlation from day to day. The present experiment re-examines this finding with other groups of animals which differed in prior behavioral and surgical treatments and examines the relationship between order of picking up and exploratory/emotional behavior as measured by the open-field test.

\section{Method}

The first group (Group 1) consisted of 25 rats which had been trained in a shuttle box at approximately 3.5 months of age and were approximately 5 months of age at the beginning of the experiment. (At 10 weeks of age $10 \mathrm{Ss}$ had sustained septal lesions, four were sham operated, and five received only an anaesthetic dose of nembutal; the remainder were normal control Ss.) The second group (Group 2) consisted of 27 animals which remained in cages for 2 months from approximately 2 months of age. All Ss were housed in pairs and were on ad lib food and water.

The feeding stand had two levels, 18 in. apart: the upper level 5 $\mathrm{ft}$ from the ground. The trays were $2.5 \times 2.5 \mathrm{ft}$.

After the Ss had been left on the upper level of the feeding stand for $1 \mathrm{~h}$ in a dark room, one $\mathrm{E}$ stood at one corner of the stand and reached for the $S$ nearest to that corner. Then the $E$ opened a door to an adjoining room, identified the animal and a second $E$ recorded the number. The $S$ was then placed on the lower level. After the first run the Ss were left for $1 \mathrm{~h}$ in the dark room before repeating the procedure, returning the Ss to the upper level. This testing was repeated for three consecutive days, and the two Es retained the same roles. Testing began at approximately $1 \mathrm{pm}$.

The day immediately following the last pick-up day 16 of each group were tested in the open-field (Glickman, 1958) for $5 \mathrm{~min}$. (The open-field was in the same room where the Group 1 Ss had been trained in the shuttle box.) The 16 were selected on the basis of the sums of squares of ranks over the six pick-up trials: the top group of the eight with the least sum of squares and the bottom group with the greatest sum of squares. Fortuitously the top and bottom eight of Group 1 consisted equally of lesioned and control Ss. All open-field tests were run by the same E during the afternoon.

Results

A Kruskal-Wallis one-way analysis of variance was applied to the sum of ranks over the six pick-up tests for Group 1 and yielded no statistically significant difference between the lesioned, operated control, nembutal control, and normal control groups $(H=4.163$, $p>.20)$.

Kendall's coefficient of concordance over the six pick-up tests yielded significant $W$-values of .614 for Group $1\left(\chi^{2}=88.474\right.$, df
$=24, p<.001)$ and of .651 for Group $2\left(x^{2}=101.478, \mathrm{df}=26, \mathrm{p}\right.$ $<.001$ ). The correlations (Rho) between tests for Days 1 through 3 were all statistically significant (one-tailed tests) and were respectively: Group $1.44(\mathrm{p}<.05), .56(\mathrm{p}<.01)$ and $.62(\mathrm{p}<$ $.01)$, and Group $2.55(\mathrm{p}<.01), .83(\mathrm{p}<.01)$ and $.62(\mathrm{p}<.01)$.

The combined subgroups of Groups 1 and 2 did differ in their response to the open-field, the Group 1 Ss showing significantly less entering of squares. The range for Group 1 Ss was 0 to 63 with a median of 2 and for Group 2 a range of 6 to 70 with a median of $36\left(n_{1}=n_{2}=16, U=44.5, p<.002\right)$. However, for Group 1 the difference between the lesioned and the control $S s$ was not significant $(U=16)$.

In comparing the top and bottom subgroups within Groups 1 and 2 the differences were not significant (Group $1, U=24$; Group 2, $U=22$ ). For bolus counts none of the possible comparisons were statistically significant.

Discussion

It is clear that rats show a consistent pattern of locating themselves in an open-field-type situation as revealed by the order of picking up by an experimenter. The consistency is independent of prior experience of behavioral treatments and of operative procedures, such as anaesthesia and surgical intervention in the septal region of the forebrain.

The comparison of the number of squares entered by the two groups indicates that prior exposure to shock does inhibit responding in the open-field and this finding is consistent with a study by Campbell \& Candland (1961) of prior shock and open-field behavior.

Unlike the latter study the differences in bolus count were not significant: this discrepancy may be due to some combination of the variables of age, extended shock period, or the length of delay between shock and open-field testing. However, more germane to this study, open-field behavior does not differentiate between the top and bottom animals as ranked for pick up from the feeding stand. Thus whether one considers open-field behavior as an index of emotionality or exploratory behavior it is not related to consistency of response in a pick-up situation.

A further possible measure would be dominance and was examined partially by studying 12 of the possible 64 pairings of the top and bottom 8 animals of Group 1. (After 23-h water deprivation for two days the $24 \mathrm{Ss}$ were placed individually in a cage with a water spout available and allowed to drink for 30 sec. The spout could be reached by only one animal at a time. The top and bottom Ss were paired haphazardly and scored for time drinking during $1 \mathrm{~min}$. Of the 12 pairs the top ranked Ss retained the spout longer ( $p=.038$, Binomial test) than the bottom ranked.) This incomplete study suggests that dominance is the variable most closely related to consistency of response to picking up.

\section{REFERENCES}

CAMPBELl, B. A., \& CANDLAND, O. K. Effect of prior shock on the emotionality of young rats in an open field. Canad. J. Psychol, 1961, 15, $1-5$.

GLICKMAN, S. E. Effects of peripheral blindness on exploratory behavior in the hooded rat. Canad. J. Psychol., 1958, 12, 45-51.

\section{NOTE}

1. The research was supported by Institutional Grant GU-712 from the National Science Foundation to Fairfield University. I wish to acknowledge the excellent assistance of Paul Handal. 